este dicho Cristóbal Gutiérrez Rojo dijere en razón de ello» ${ }^{14}$. Especial interés tiene este párrafo, pues ilustra acerca de lo que en ese período supuso para muchos pintores el mercado americano como salida comercial para su trabajo, ante el competitivo mercado artístico de la corte. El tono de la frase y la confianza que nuestro pintor deposita en el intermediario o marchante, prueba la existencia de una fluida y larga relación comercial entre ambos ${ }^{15}$.

El último documento en relación con Jerónimo López es la anotación consignada el catorce de abril de 1626 en el libro de enterramientos de San Miguel, libro conservado en la parroquia de San Justo de Madrid: «En la calle de la Compañía (...) murió Gerónimo López, pintor (...) mandó enterrarse en su sepultura en San Miguel (...) mandó cien misas de alma y cuatrocientas ordinarias. Testamentarios Andrés López, pintor (...) y Cristóbal Ruiz, mercader de lienzos» ${ }^{16}$.

Todo lo aportado nos ofrece el perfil, aún incompleto, de un notable pintor madrileño del primer tercio del siglo XVII cuyo catálogo se compone, hasta el momento, por tres obras seguras y una cuarta con muchas posibilidades de ser incluida en el mismo, el retrato de Juan de Briviesca conservado en Madrid.

Comparando dos de estas obras, el retrato de Briviesca y la Inmaculada de Dueñas, descubrimos en esta última ciertas novedades respecto a la primera, novedades que se explican tanto por la diferencia en cuanto a tema o finalidad de las mismas, como por percibirse cierta evolución en la trayectoria del autor. Así, en cuanto al color, aunque siempre comedido, sustituye la austeridad dominante en el retrato del Museo del Palacio Episcopal por el sutil cromatismo que envuelve la composición de la Inmaculada de la Iglesia de la Asunción de Dueñas. Esta obra, interesante en su conjunto, alcanza altas cotas de calidad en algunos fragmentos especialmente bellos, como el grupo de cabezas de querubines situadas a los pies de la Virgen, las flores de la parte baja de la composición, o el mismo rostro de la Virgen, todos ellos tratados con un sobrio y elegante estilo naturalista ya presente en el retrato del clérigo Juan de Briviesca.

Pintor con la suficiente calidad como para haber conseguido destacar en el ambiente artístico madrileño del primer tercio del siglo XVII, su figura se nos muestra hoy algo más definida, aunque aún sin la claridad con la que sus obras reflejan su maestría.

CARLOS SÁNCHEZ DíEZ

Museo «Palacio Episcopal», Segovia

\title{
JUAN DE BORGOÑA, PEDRO CISNEROS Y CRISTÓBAL DE VILLARREAL EN GALAPAGAR (MADRID)
}

Desde que don Diego Angulo Íñiguez publicase hace poco más de cuarenta años su valiosa monografía sobre Juan de Borgoña, no se ha vuelto a afrontar una visión global de esta personalidad clave para la pintura del renacimiento castellano ${ }^{1}$. Quedan todavía por clarificar, como

\footnotetext{
14 (1626-IV-1, Madrid) Archivo Histórico de Protocolos. Protocolo número 5874, fóls. 9-11. Testamento de Jerónimo López Polanco.

${ }^{15}$ No es de extrañar la presencia de una obra de Jerónimo López Polanco en Canarias, escala del viaje a América.

${ }^{16}$ Agulló y Cobo, M., op. cit., p. 89.

1 D. Angulo Íñiguez, Juan de Borgoña, Madrid, 1954. Antereior a la obra de Angulo, C. R. Post, «The beginning of the Renaissance in Castille and Leon», en A history of spanish painting, vol. IX, I, Cambridge, Massachusetts, 1947, pp. 162-234, donde se incluye la bibliografía anterior.
} 
afirmó hace ya veinte años Fernando Marías ${ }^{2}$, aspectos múltiples y vitales de la biografía del pintor, como su origen, no precisado todavía con exactitud, y formación que, se supone, completó en tierras italianas antes de pasar a España ${ }^{3}$.

Por el contrario, han sido varias las publicaciones que han completado aspectos puntuales del devenir vital y creativo del pintor radicado en Toledo. La noticia que aportamos quiere sumarse a estas últimas y ayudar a completar el cuadro general sobre el gran pintor «español» 4 .

Entre los legajos del escribano madrileño Diego de Soto, se encuentra una breve noticia que vincula al pintor borgoñón con la realización de un retablo para la iglesia parroquial de Nuestra Señora de la Asunción, en el pueblo madrileño de Galapagar ${ }^{5}$.

Por estos documentos sabemos que Juan de Borgoña había contratado la obra de pintura de un retablo, cuya ejecución parece que estaba dividida a partes iguales entre él y Cristóbal de Villarreal, huidizo pintor madrileño de cuya obra, principalmente desarrollada en la archidiócesis de Toledo y, especialmente, en el área madrileña, nada ha llegado hasta nosotros ${ }^{6}$.

En concreto, la documentación expone las gestiones realizadas por Cristóbal de Villarreal ante los herederos de Borgoña, muerto durante la realización del retablo. El 8 de diciembre de 1536 da un poder a su hermano, el también pintor Diego de Villarreal, para, en primer lugar, requerir 11.000 maravedises que había prestado a Borgoña y su discípulo Pedro de Cisneros «en pago de lo que se montase el hacer de la mitad del dicho retablo» y, por otra parte, reclamar «las seis pieças que del dicho retablo los dichos herederos tienen que se las dio Juan de Obregón, entallador que hace la talla del dicho retablo» ${ }^{7}$.

La aparición de Juan de Borgoña en Galapagar viene a sumarse a sus intervenciones ya conocidas en la zona madrileña. En febrero de 1521 contrató la hechura de un retablo para la capilla que en el monasterio de Santo Domingo el Real de Madrid poseía Pedro Hurtado, mayordomo del convento ${ }^{8}$. Del 24 de abril de 1522 es el contrato del retablo para la iglesia de Parla. A éste, sigue el que se obligó a hacer el 29 de enero de 1525 para la capilla de los Vozmediano en la iglesia de Santa María de la Almudena ${ }^{9}$. Completan la obra de Borgoña en el actual territorio de Madrid los retablos que se le encargaron para la parroquial de Villa del Prado: el del altar mayor datado entre 1518 y 1523 , y uno de los dos retablos colaterales, realizado entre 1534 y $1535^{10}$.

\footnotetext{
${ }^{2}$ F. Marias, «Datos sobre la vida y obra de Juan de Borgoña», Archivo Español de Arte, XLIX, 194, 1976, pp. 180182.

${ }^{3}$ Sobre el periplo seguido por Borgoña en Italia, D. Angulo Íñiguez, op. cit., y aportando otro punto de vista, A. Condorelli, «Il problema di Juan de Borgoña», Commentari, XI, 1960, pp. 46-59.

${ }^{4}$ J. M. Azcárate, «Una traza de Juan de Borgoña», A.E.A., 81, 1948, pp. 55-58; C. R. Post, «Juan de Borgoña in Italy and Spain», Gazette des Beaux-Arts, XLVIII, 1956, pp. 129-142 y XLIX, 1957, p. 208; D. Angulo Íñiguez, «Pinturas del siglo XVI en Toledo y Cuenca. Juan de Borgoña y su escuela. Pedro de Aponte en Atri. Yáñez y Sebastián del Piombo», A.E.A., XXIX, 113, 1956, pp. 54-58; A. Condorelli, art. cit.; J. Caamaño Martínez, «Sobre la influencia de Juan de Borgoña», Boletín del Seminario de Estudios de Arte y Arqueología, 1964, pp. 292-305; R. Longhi, «Per Juan de Borgoña», Paragone, 189, 1965, pp. 65-71; J. C. Gómez-Menor y Fuentes, «Algunos documentos inéditos de Juan de Borgoña y otros artífices toledanos de su tiempo», Anales Toledanos, II, 1968, pp. 163-183; A. E. Pérez Sánchez. «Sobre una obra de Juan de Borgoña», Arte Español, XXVI, 1968-1969, pp. 13-14; J. C. Gómez-Menor y Fuentes, «Un monumento artístico de-

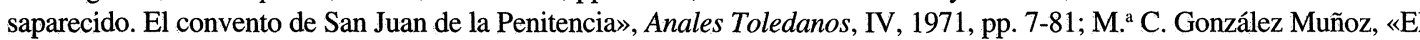
antiguo retablo de la Colegial de Talavera. Posible obra de Juan de Borgoña», A.E.A., XLVII, 185, 1974, pp. 53-56; F. Marías, art. cit., J. M. Cruz Valdovinos, «Retablos inéditos de Juan de Borgoña», A.E.A., LIII, n. ${ }^{\circ} 209,1980$, pp. 27-56; I. Mateo Gómez, «Juan de Borgoña, autor del retablo del monasterio de San Miguel de los Ángeles de Toledo», en Miscelánea de Arte, C.S.I.C., Madrid, 1982, pp. 75-79.

5 Archivo Histórico de Protocolos de Madrid (A.H.P.M.), Prot. 120, fol. V y fol. VI.

${ }^{6}$ Sobre la actividad de Villarreal en Madrid se prepara un próximo trabajo.

7 A.H.P.M., Prot. 120 , fol. VI.

${ }^{8}$ M. Estella, «Los artistas de las obras realizadas en Santo Domingo el Real y otros monumentos madrileños de la primera mitad del siglo XVI», Anales del Instituto de Estudios Madrileños, XVII, 1980, p. 43.

${ }^{9}$ J. Gómez-Menor y Fuentes, art. cit., pp. 174-175 y 176.

${ }_{10}$ J. M. Cruz Valdovinos, art. cit., 1980, pp. 43-48.
} 
Desgraciadamente de todos estos retablos no conservamos ningún resto. En el caso de Galapagar es posible que el retablo, que no sabemos si fue finalmente realizado, se contase entre los que fueron quemados por los franceses en la Guerra de Independencia ${ }^{11}$.

El encargo debió partir de la propia iglesia que, seguramente, por tener un retablo ya viejo, pediría al visitador eclesiástico que se gestionase ante el cabildo toledano la posibilidad de realizar uno nuevo ${ }^{12}$. Es esta posible gestión de la contratación de la obra a través de Toledo lo que explicaría la llamada a Borgoña y su taller.

El documento señala, como se ha visto anteriormente, que la obra la tomaron a hacer conjuntamente Borgoña y Villarreal, repartiéndosela a partes iguales. Nuestros conocimientos sobre la figura de Villarreal, dificultados por la inexistencia física de su obra, nos llevan a pensar que trabajaba indistintamente como pintor de tablas y como pintor de imaginería. Creemos más posible que en Galapagar se ocupase únicamente del trabajo de pintura sobre las tallas, habida cuenta de la importancia del taller de Borgoña, que se bastaría para ejecutar las tablas. Apunta en esta dirección el hecho de que reclame a los herederos de Borgoña las piezas que ya están hechas del retablo para, a buen seguro, poder completar la parte que a él le tocaba en el mismo.

En cualquier caso, en la parte de pintura que tomase a su cargo Borgoña, ya fuese su totalidad o la mitad, la intervención del taller debió ser muy importante. Teniendo en cuenta la cronología del retablo y, valorando la presencia de Pedro de Cisneros en el documento como receptor, junto a Borgoña, del dinero dado por Villarreal, esta hipótesis se hace más que verosímil ${ }^{13}$. Por lo tanto, nos parece que la aportación de Borgoña a la obra debió limitarse a labores muy precisas, en caso de que llegase a ejecutar alguna parte de la misma antes de morir. Este sistema de trabajo, a través del taller, es el habitual de Borgoña en los últimos años de su dilatada carrera, lo que le permitía, como queda demostrado por la documentación, tener en estos años varios retablos más en ejecución, además de el de Galapagar. Es el caso de los retablos de Escalona y Cuerva, en la provincia de Toledo, inacabados a su muerte y encomendada su terminación a su hijo Juan ${ }^{14}$, Pastrana, en Guadalajara, y el retablo colateral de Villa del Prado ${ }^{15}$.

De entre éstos fue, sin duda, el de Pastrana el de mayor importancia y en el que Juan de Borgoña realizó mayor labor personal, pues así estaba obligado por el contrato. Esto explica la elevada suma que por él recibirían Alonso de Covarrubias y Borgoña, 267.500 maravedises ${ }^{16}, \mathrm{y}$ que contrasta enormemente con la percibida por el retablo de Galapagar. Es este aspecto, el económico, otro dato que abundaría en la probable delegación por parte de Borgoña de la factura de la obra a Pedro de Cisneros, y se puede argumentar con mayor equidad comparando el retablo de

11 En 1839 don Antonio Uñach y su mujer María Teresa Carbonell, vecinos de Galapagar, donaron un nuevo retablo para el altar mayor, sin él desde la francesada. Archivo Diocesano de Madrid, Galapagar, Carp. 4. Este retablo, según la documentación consultada, era una de los regalados por Fernando VII a la iglesia madrileña de San Felipe Neri. Por otra parte, creemos que el retablo documentado por A. Matilla Tascón, «Documentación sobre pueblos de la provincia de Madrid en el Archivo Histórico de Protocolos», A.I.E.M., XXII, 1985, pp. 307-412, se destinaría a la capilla de la Cofradía de Nuestra Señora, cuyos mayordomos contratan la obra, y no al altar mayor de la parroquial.

12 Sobre la iglesia de Galapagar, A. de la Morena Bartolomé, La arquitectura gótica en la provincia de Madrid, Madrid, 1974, p. 21.

13 Sobre Pedro de Cisneros, C. R. Post, A history..., op. cit., vol. IX, I, pp. 296-302. Más recientemente, I. Mateo Gómez, «Cuatro tablas de Pedro de Cisneros en la iglesia de Valdemoro», A.E.A., 229, 1985, pp. 44-51.

14 F. Marías, art. cit., p. 181.

15 Para los retablos de Santa María de Escalona y Pastrana, J. Gómez-Menor y Fuentes, art. cit., p. 168. El de Cuerva en F. Marías, art. cit., p. 181. El de Villa del Prado en J. M. Cruz Valdovinos, art. cit., 1980, pp. 43-48, quien amplía todo lo relativo al de Pastrana, pp. 48-52.

16 J. M. Cruz Valdovinos, art. cit., 1980, p. 54. 
Galapagar con el colateral de Villa del Prado, realizado poco antes y quizá de tamaño similar, por el que se pagaron a Juan de Borgoña 34.027 maravedises ${ }^{17}$.

LuIS ZOLLE BETEGóN

Universidad Autónoma de Madrid

\section{ARQUETA FLAMENCA DE LOS CINCO SENTIDOS EN ALCALÁ DE HENARES}

En la Iglesia Magistral de Alcalá de Henares se conserva un precioso cofrecillo de marfil, una de las piezas más finas de las conservadas en España de por los años finales del siglo XVI. De base rectangular, presenta la tapa combada y aparece recubierta de planchas de marfil sobre armazón metálico. En cada frente y en la tapa se representa una escena sobre un precioso fondo de decoración manierista enmarcada por simples molduras. La estructura metálica, refuerza al exterior, con molduras rectilíneas, las superficies talladas en el marfil de los frentes, laterales y tapa. Asienta sobre bolas, con bella cerradura y asas a los lados.

En un principio los temas representados en sus superficies plantearon problemas de identificación por lo que se analizaron con detenimiento. La plaqueta del frente de la arqueta representa una bella figura femenina sentada delante de una gruesa columna mirándose en un espejo. En el primer plano un águila con las alas desplegadas y de tamaño desproporcionado en relación al de la figura vuelve su cabeza hacia ella. Un fondo de paisaje marítimo, con una barquichuela con velas y a su derecha arquitecturas simulando una ciudad, completan la escena. En la del reverso se representa una figura sentada con el brazo extendido cuya mano picotea un pájaro. Al fondo, a la derecha, árboles cuyas ramas cobijan una telaraña. Una tortuga en primer término y a la izquierda una barca encallada en la orilla con las redes en la borda, sobre el agua que al fondo delinea la costa y una isla con edificios humeantes. En la tapa una figura femenina coronada de una guirnalda de flores acerca hacia sí unas ramas de un jarrón sosteniendo otro semejante con flores sobre sus piernas. a su derecha dos perros, uno de los cuales apoya sus patas en el recipiente olisqueando las flores, destacando sobre un fondo de árboles y edificios. En una de las plaquetas de los laterales, una fina figura de mujer toca el laúd observada por un ciervo. A sus pies una trompeta doblada en $« \mathrm{~S} » \mathrm{y}$ una viola de «braccio» con una partitura musical abierta ${ }^{1}$. La escena del otro lateral representa una mujer con los senos desnudos, sentada y comiendo, mientras sostiene con su mano un cesto de frutos ante el que se representa una jarra y una copa. En el ángulo inferior derecho un mono, también comiendo, aparece ante otra cesta con alimentos (Figs. 15-16, 22-23).

La identificación de estas escenas con la representación de los Cinco Sentidos ha sido relativamente fácil por los símbolos que las acompañan. En la primera descrita, el espejo en el que se mira la figura y el águila, ave cuya vista aventaja a las de su especie y que puede mirar al sol de frente, aluden al sentido de la Vista que puede deleitarse en la contemplación de un amplio paisaje. La representación del Tacto por el pájaro que pica la mano y produce dolor fue en realidad una innovación iconográfica renacentista que identifica en esta sensación la más exacta re-

\footnotetext{
17 Ibidem.

${ }^{1}$ La doctora Rosario Álvarez, Catedrático de Musicología de la Universidad de la Laguna, me indicó amablemente el tipo de instrumentos representados.
} 